\title{
The Strategies of Standard Management of Practical Teaching Drama "Silk Road • The Youth"
}

\author{
Du Chen
}

Dalian Art College, Liaoning, Dalian, 116600

Keywords: Large-scale stage practice; Teaching program; Standard management; Strategy

\begin{abstract}
The teaching and performance of Silk Road • The Youth is cited as an example in this paper to summarize and explore characteristics and rules of practical teaching in art college, thereby forming a set of practical and feasible standard management mechanism of practical teaching, institutionalized and systematized. This is also the important insurance for great and sustainable development of art college and the ultimate purpose of this topic.
\end{abstract}

\section{Introduction}

Silk Road • The Youth is the cultural pillar of Dalian Art College, which is a private art college, in "Belt and Road" conception, and it is the sufficient performance of innovation inheritance of college culture. Through diversified performance of stage art, Chinese culture and art is publicized and carried forward better from the perspective of college students. Therefore, Chinese stories are narrated, Chinese history is understood, Chinese national conditions are understood and Chinese elements are integrated into the development and construction of Belt and Road.

The performance of Silk Road $\bullet$ The Youth is of great influence and milestone significance to the development of the college as well as practical implementation and construction of the country's proposal of "Belt and Road" top design. The president of the college has spared no efforts to make it exquisite so that it can become the sign and characteristic brand during the development and reform of Dalian Art College. The rehearsal process is of great importance to the philosophy and practical cultivation of art talents. The college treats practical teaching of art as characteristic and key construction, thereby forming the practical teaching mode of creation performance as platform, stage as classroom, performing mobilizing practice and promoting teaching. It is a necessary course, during which students can be promoted from being able to merely grasp singing or performing techniques to being equipped with individual and independent thinking, emotional awareness and performing qualities, and it is an inevitable road from passive training to active performing.

\section{The necessity of integrating Silk Road $\bullet$ The Youth into teaching program and standard management}

The orientation purpose of talent cultivation in our college is to cultivate applied art talents, and the school-running characteristic is to construct "studying, performing, competition and creation-integrated practical teaching system". However, the realization of the purpose and the manifestation of school-running characteristic both requires the process of creating qualified drama_-making qualified drama and promoting qualified drama. Drama teaching happens to be an important teaching mode with most integrity, practicalness and performability in the curriculum system of music performance major. Therefore, we need to create and promote new dramas continuously, integrate them into teaching and make them normalized, and this has become one of the important tasks of scientific researches of our college. However, there might be some time clashes between drama teaching and normal teaching sometimes, so it needs standard management. Only by scientific and standard management can we avoid clashes and blindness, thereby making practical teaching more scientific and improving teachers' and students' art skills. The necessity of standard management is represented in:

Firstly, standard management contributes to "studying, performing, competition and 
creation-integrated practical teaching system". The construction of the system requires a set of scientific, reasonable and feasible management methods. Teaching approaches need to be reformed and innovated, courses and rehearsal time need to be arranged reasonably, and teaching outline and textbooks need to be formulated, thereby exerting the important function of drama teaching in the process of talent cultivation, manifesting school-running characteristics of the college and promoting new dramas continuously.

Secondly, standard management contributes to the performance effects of large-scale dramas. Drama rehearsal cannot be neglected in the implementation and quality monitoring process of practical teaching. A large-scale stage drama involves personnel and work of the creation team, performance staff, logistical support, costume designing, stage direction, property preparation, site environment, curriculum adjustment and so on. For the purpose of successful coordination, standard management is needed by professional personnel and agencies. Therefore, the task can be completed with high quality and good performance effects can be achieved.

Thirdly, standard management contributes to the improvement of students' professional ability. The classroom for applied art talent cultivation should be a studying-performing-integrated platform of classroom and practice. No matter macroscopically or microscopically, practical teaching of large performance is very necessary. Macroscopically, the rehearsal hall and big theaters are used as classrooms; students can listen to the classes of national and global masters, feel team work spirit, work out their experiences in performances and improve their accumulated experiences continuously, which cannot be learned in classroom teaching. Microscopically, from large-scale interviews, we can see the studying enthusiasm and rapid progress of every student in the performance, which cannot be seen in classroom, either.

\section{Investigation and analysis on standard management with Silk Road •The Youth as an example}

The investigation mainly aims at students' enthusiasm in large drama rehearsal; standard curriculum management and reform of teaching forms; the improvement of students' knowledge and skills from large dramas; the improvement of teachers' professional abilities from large dramas and management of rehearsal organization. Interviews and questionnaires are adopted for investigation on symphony orchestra, dance troupe, chorus, costume design team, property production team, drama insurance team and so on. 350 questionnaires are handed out, and 330 effective questionnaires are collected, so the effective rate is $94.3 \%$.

The investigation data shows that $87.1 \%$ students are willing to join in the rehearsal, and $12.9 \%$ are unwilling to. As for the reasons of the willingness: 244 people believe that it can endow them with practical stage experience, 139 people believe that it can help them with finding a good job after graduation, 130 people like the flexible learning form, and 93 people think that it can add credits for them.

214 students believe that their personal skills are improved, 152 students believe that their teamwork spirit of chorus (ensemble) is enhanced, 109 students believe that their organizational and management abilities are improved, 99 students hold that their music theories and cultural qualities are enriched, and 97 students show that their solfeggio and ear training standard is improved.

According to the data, 130 students show that their teachers' teaching is more pertinent, 155 believe that the classroom atmosphere is more active, 163 students indicate that teachers pay more attention to motivating students' initiative, 92 believe that the frequency of professional demonstration has risen, and 34 believe that they benefit more from more teachers' teaching.

In the investigation on the organization and management, the data shows that 67.74 people are satisfied, $25.81 \%$ believe that it is common, while $6.45 \%$ are dissatisfied.

Students at French Horn said, "In the orchestra rehearsal, I was guided by Mr. Wang Guan in person, who is a well-known French Horn performer, and I improved quite a lot." Students at Folk Music selected cello and bass for the second major, but they were completely qualified for the performance after long time of rehearsal and careful instruction from various teachers, and the students felt great sense of achievement! Two teachers at Sax learned Basson by themselves with 
the guidance and encouragement of the conductor, then they joined the rehearsal; teachers at bamboo flute also learned from Mr. Wang Guan for French Horn. After years of performance and exercise in the orchestra, they have become the backbone of the orchestra.

From the above data analysis and face-to-face interview, the following conclusions can be acquired:

Students show great interest in the new teaching mode, teaching methods and stage experienced teaching;

Students have a clearer goal for their self-development orientation, career planning and professional skills after art practice and drama teaching;

The art practice and teaching process have promoted the improvement of teachers' development awareness, innovation of teaching forms, update of teaching content and improvement of teamwork spirit.

\section{Standard management approaches and resolution strategies of large drama practical teaching}

Management layers value drama teaching and conduct overall planning and reasonable scheduling.

Silk Road•The Youth is a large-scale piece of work, which involves with many majors, teachers and students. Therefore, a comprehensive, systematic and feasible project needs to be formulated in advance. Drama creation, arrangement, rehearsal, performance, logistics support, budget, staff composition, curriculum adjustment, afterward conclusion and so on all need planning ahead of schedule. Macroscopic purposes and microscopic details are both needed.

Silk Road•The Youth drama teaching requires outstanding double capability teachers with both rich performance experiences and certain teaching and arrangement abilities. Besides completing performance task, the teachers should also transform relative theoretical knowledge to practical guidance, transform classroom management to stage control and transform from a teacher to an instructor, thereby stimulating and motivating students' self-creativity, knowledge application ability, resilience, coordination ability, communication ability, management ability and so on, reaching good teaching effects and improving teaching quality gradually.

The design philosophy of drama teaching is to follow the design thinking of integrity, stage, continuity, hierarchy and progressiveness, formulate the curriculum outline of drama teaching, further make clear curriculum purpose and teaching task, optimize curriculum content, enrich psychological training content of the performance and further specify assessment standards, thereby making drama teaching outline more scientific and reasonable and realizing the ultimate goal of improving teaching quality.

Formulating rules of curriculum outline of Silk Road•The Youth, summarizing and formulating "textbook selection and construction system of drama teaching", "marketization management system of large-scale drama performance".

"People oriented" should be the highest principle when resolving he contradiction between performance and normal schedules. It should start from career planning of students and actors with service as the starting point. The following strategies are proposed:

(1) Implementing teaching hierarchically, creating personalized training plans for top-notch innovative personnel of music performance majors

Designing training plans which conform to individual development for students who often join in drama performance and have outstanding professional abilities is beneficial for teachers to teach students in accordance of their aptitude; it is also conductive to students' individual development and the college's outstanding teaching characteristics. Meanwhile, the "one student and many teachers" teaching system for top talents is established, and the new and comprehensive teaching mode on the stage in the spotlight is created. The traditional single training mode of "platform courses + specialized courses" is changed, and the hierarchical talent training plans of different directions is constructed, i.e., the training mode of "specialized basic platform + specialized skill mode + career extension mode + autonomous practice mode". Under the condition of unchanged 
major categories, three hierarchies of A, B and C are divided from each major according to students' standard and degree and individual employment intentions; different teaching aims are established and corresponding teaching methods and curriculums are implemented. For students who have not joined in the performance, students are taught by integrating classic drams into syllabus and teaching materials; they can also learn from practice by joining in teaching concert; besides, they can imitate and learn by rehearsal and observation lessons.

(2) Adopting multiple teaching methods, identifying credits flexibly and motivating students' enthusiasm in performance

Firstly, adopting Internet classes and making up part of the required courses, which is not restricted by time and space and students can make full use of spare time. Secondly, inviting music and performing artists, dancers, historians and writers from the province and out of the province for lectures regularly so that students can have full confidence in their career. Besides, the lectures can also broaden students' horizon and students can get in contact with some extended knowledge, which cannot be contacted at ordinary times, and their interest in learning can also be enhanced. Thirdly, students should be organized for performance and be arranged for communication in local museums, art galleries, higher art colleges, during which they can explore cultural and local customs of different places; meanwhile, their observation, imagination and art expressive force will be trained. Fourthly, teachers should be required to arrange one-to-one classes reasonable so that every student's specialized courses can be ensured. From the above forms, students' credits can be confirmed flexibly, and students can have a profound understanding that they can learn much knowledge and experience which cannot be learned in classes and books. Thus, their enthusiasm in performance will be enhanced.

(3) Standardizing drama teaching management, integrating classic dramas into syllabus and textbooks

Specific methods: writing practical programs of Silk Road•The Youth according to tasks and majors; formulating syllabus of Silk Road•The Youth according to programs, including teaching content, exam requirements and so on; including Silk Road•The Youth into classroom teaching plan; formulating timetable; producing standard teaching plans of Silk Road•The Youth; having the materials and school reports of the practical teaching assessment of Silk Road•The Youth; having records, pictures and videos of various levels of leaders attending the classes and checking classes; having relative materials, pictures and videos of practical teaching achievements reports of Silk Road•The Youth; having materials, certificates, pictures and videos of practical teaching achievements; having work reports of practical teaching of Silk Road•The Youth. Transforming advantages of teaching to normal teaching, thereby forming comprehensive whole process management, innovating new system, new modes and new methods of applied art talent cultivation.

(4) Establishing standard management system of drama teaching, ensuring successful rehearsal and performance

Firstly, establishing all staff management system of multi-agent linkage. Strengthening engagement and integration. Multi-agent linkage is an open system, and each agent restricts and cooperates with one another. The management functions of the above departments learn from each other's strong points and offset each other's weak points, thereby exerting maximum function. Secondly, establishing comprehensive multi-dimensional whole process management mechanism. Integrating classroom teaching with practical teaching so that students can learn classic dramas in classes, performing classic dramas in practice and studying classic dramas in graduation papers, thereby establishing whole process management mechanism. Thirdly, establishing diversified assessment and evaluation management mechanism. Establishing standards of assessing students' practical abilities from multiple aspects; valuing process assessment of rehearsal and performance, setting up special assessment organizations and valuing equity and fairness of assessment; strengthening final assessment of drama teaching. Enlarging the portion of drama assessment in graduation assessment. In the past, only quality and paper defense are assessed; currently, it should be changed to the assessment of both quality and paper defense and "graduation performance of dramas". 


\section{Conclusion}

Silk Road•The Youth is another masterpiece of our college's practical teaching, and it has opened up relative researches of our college in drama teaching reforms; the college has also begun to explore the important function of practical teaching to talent cultivation as well as institutionalized, standard and scientific management mechanism of college drama teaching system, thereby laying basis for long-term, ordered and sustainable development of the college and exploring a new road for promoting college's service to the society.

\section{References}

[1] Wang Xianjun. Competency-based, Employment first ---The Cultivation of Applied Art Talents in the Practical Teaching of Arts. Art Education ISSN: 1002-8900.2012, No. 5. 27-30.

[2] Wang Jing. On Practical Teaching of Arts. Art Education ISSN: 1002-8900.2012, No. 3. 39-41.

[3] Xu Baohui, Bao Yu, Zhou Bin. Standardizing Management Research on Practical Teaching of Art Design Major. Journal of EMCC, ISSN: 1008-813X. 2013, No.1.

[4] Duan Youfang. The Cultivation of Music Innovative Talents in Practical Teaching Mode of “Four Combinations”. Journal of Hubei Engineering University. ISSN: 2095-4824. 2013, No. 3. 